\title{
Industry Funding of University Research: Can It Replace Federal Funding?
}

\author{
James A. Roberts
}

Vice Provost for Research, University of Kansas

$\mathrm{T}$ he question addressed in this paper came about as a result of two events. One was the presentation and paper at last year's Merrill Conference by John Wiley, Chancellor of the University of Wisconsin-Madison. He, in good engineering form, applied some engineering principles to answering a question related to the privatization of universities. ${ }^{1}$ Since I am also an engineer, I thought I could perhaps apply Chancellor Wiley's approach to a question related to the topic of this year's conference...the future of federal funding of research.

It was not long before the second event occurred. In May of this year, Dr. John Marburger, President Bush's Director of Science and Technology Policy, spoke at the Policy Forum of the American Association for the Advancement of Science (AAAS). ${ }^{2}$ The appendix contains selected excerpts from his talk, in which he asserts that the federal government cannot continue to grow sponsored research at American universities at the rate it has been. In fact, he states that we can do all the $R \& D$ we need to do but he doesn't believe that we can accomplish it by simply appropriating more federal funds. He talked about the NIH increase, stating he couldn't see how such an expansion can continue, using the same business model that got us here. All universities are going to have to look to diversified sources of income, he said, working toward the notion of industrial funding of research. And then he gets into "economically relevant outcomes," comments we often hear on the local level.

There is no argument with the positive correlation between industrial research and economic productivity. And, yes, industrial research is good for the economy, and industrial sponsored research is good for universities. What Marburger is saying is that federal funding is not going to grow fast enough to keep up with the established pace, so state and private sector resources are going to have to replace federal funding.

Toward the end of his talk, Dr. Marburger said that even though we need industrial funding of research, the amount remains low relative to its potential. Dr. Michael Crow, President of Arizona State University, spoke in Kansas City this past week. ${ }^{3}$ After his talk, I asked him about this issue and he 
agreed that industrial funding to replace federal funding couldn't be the entire answer. He added that the states need to step up and do things such as the establishment of an Arizona Science Foundation. But, as we shall see, state support of university research is low as well. So, let's just look at the numbers. Can industry-funded university research replace federally funded university research? If so, what might be the consequences?

Setting the Stage The words to the Kansas state song, "Home on the Range," state categorically, "... for never is heard a discouraging word..." I apologize for having to utter one in Kansas, but the discouraging word is a serious concern. The latest funding information for U.S. universities, compiled by the National Science Foundation, was just released. Fig. 1 is a graph of federal research and development (R\&D) obligations to universities and colleges. The discouraging message is that for the first time since 1970, there was a decline in federal funds going to U.S. universities and colleges for research. I mentioned this in a speech I made recently following remarks given by Rep. Nancy

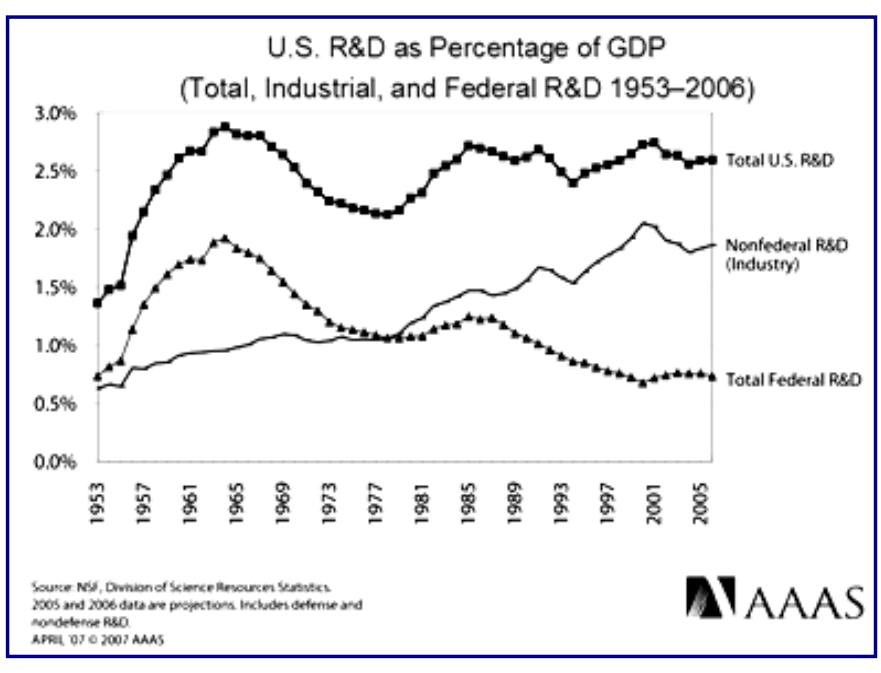

Figure 2 Boyda, Congresswoman from the Second District of Kansas. She was alarmed and wanted to see this information. These are nominal dollars, not inflated. Obligations roughly approximate federal sponsored program

percent of R\&D funded by industry has been growing the percent funded by the federal government has been declining, basically since the early 1960s, the postSputnik era. These data indicate that the 
U.S. is maintaining its research output at a more or less constant percentage of the GDP $(2.5 \%)$, and that industrial research stagnated. But let's look at this differently and ask what fraction of university research funding comes from

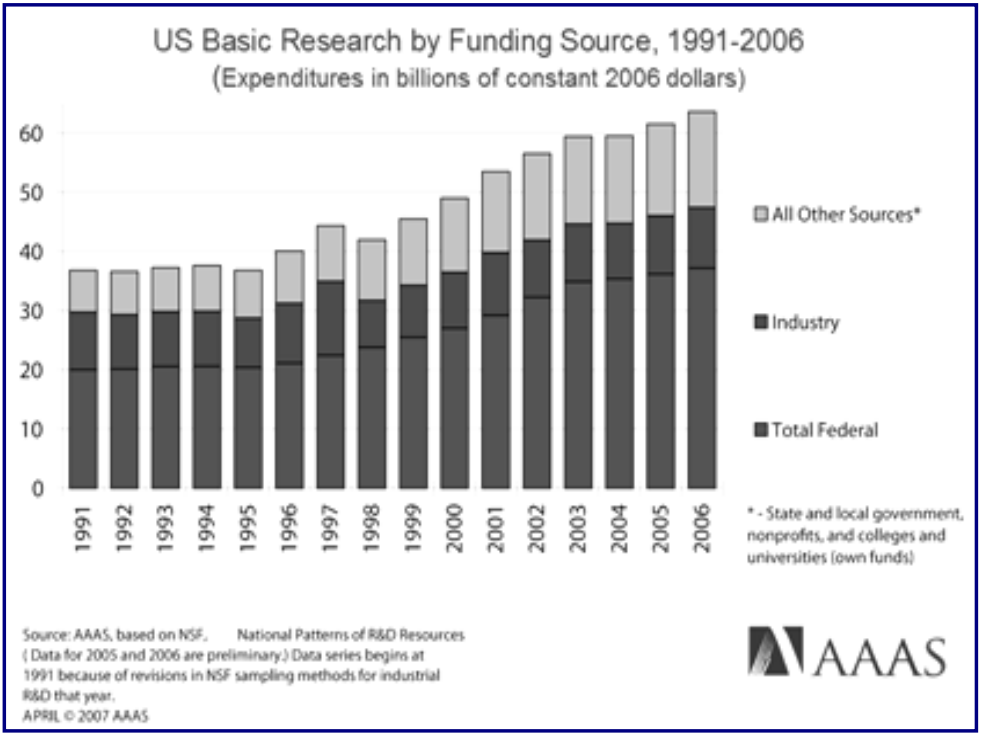

Fiqure 3

is indeed replacing federally financed research. But there are deeper implications with respect to basic versus applied research and funding of universitybased research. Basic research funding is growing as well. Fig. 3 shows data from an AAAS chart that confirms this. But note that the industrial component has not changed much. Growth is coming from federal and other sources, not industry. Fig. 4 plots industrial sponsored R\&D at colleges in universities in nominal dollars, going back to 1972. The good news is that it grew from something that wasn't very much at all to a substantial amount, and it grew fairly steadily until 2000. After the dot-com bust, though, it has industry. Fig. 5 plots this percentage, and now the picture is not as pretty. The percentage has in fact declined from a paltry $1.5 \%$ in the early $1990 \mathrm{~s}$ to where it now hovers at about 1\%. Plain and simple, industry is not, in general, a major source of funding for university research.

\section{A Look at the Numbers}

To analyze the question of industrial funding making up for a slowdown in federal funding of university research, assume that overall university research funding continues to

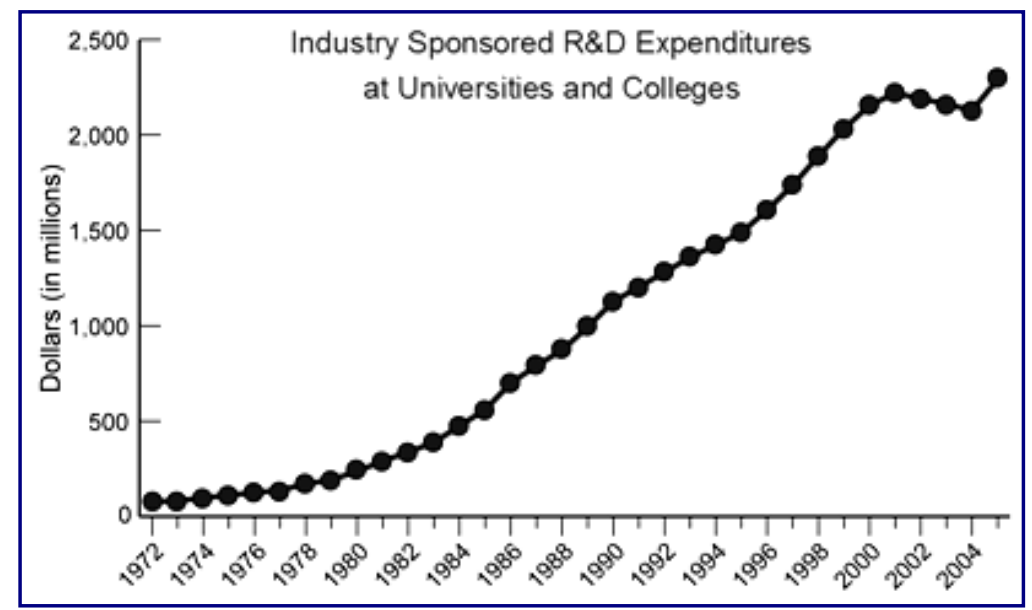

Fiqure 4

grow at its historic rate through 2013. In addition, assume that federal funding of research flattens, as it has recently, but allow state and other sources to grow at their historic rates. Then calculate the size of the industrial component needed 
to pick up the slack from the flattening of federal funding.

A useful device is to plot the historical data on a logarithmic scale. Fig. 6 shows such a plot for the data plotted on a linear scale in Fig. 1.
And the results, in terms of the strength of the U.S. economy and improvement in our standard of living, have been spectacular.

Fig. 7 shows the results of the analysis based on the assumed scenario.

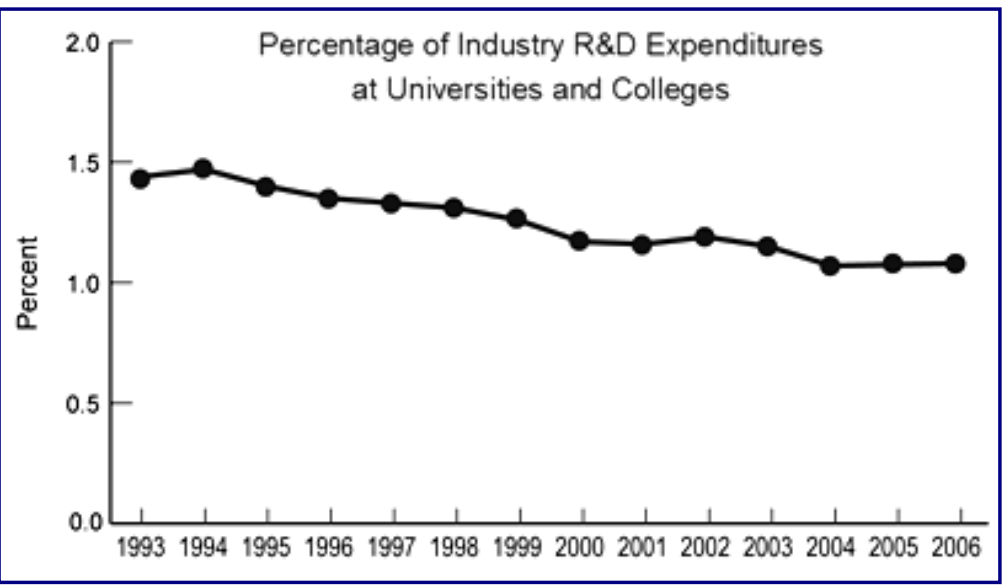

Fiqure 5

Again, the total research funding level grows at the historic rate, as do state and other sources. Federal funding flattens, and industrial funding is computed to maintain the total. In order to do that, industrial funding of university research would suddenly have to begin growing at $40 \%$ annually, compared to an annual

Exponential growth is a straight line on a logarithmic scale, and so we see that from the mid-1960s until about 2005 federal funding of university research grew exponentially. The approximate slope of the line indicates an annual growth rate of about $8.1 \%$.

This is a measure of the 40-year commitment on the part of the federal government to fund university research.

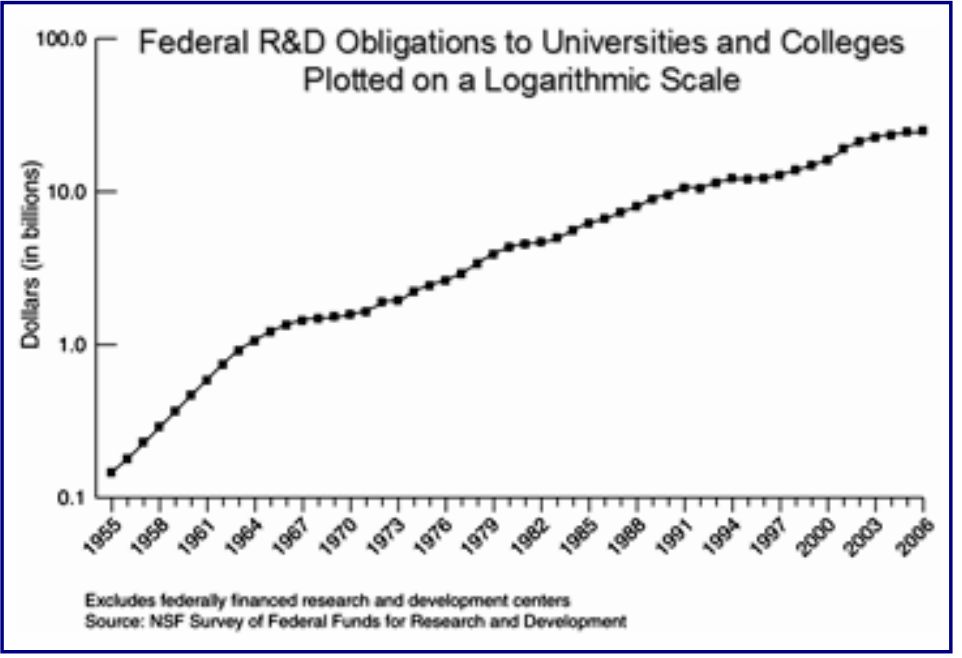

Figure 6 growth rate of $4.4 \%$ over the past 10 years. And in the end, by 2013, industrial funding would actually exceed federal funding. This simply isn't going to happen. And why would industry do this anyway? They are not a charity out to replace funding for the collective national good just because the federal government has decided not to do it.

\section{Unintended Consequences}

For the sake of argument, let's go ahead and assume industry were in fact to make up for the reduced federal funding at universities. What are the unintended consequences of this "good" outcome? Three questions immediately come to mind:

- What happens to funding levels in specific 


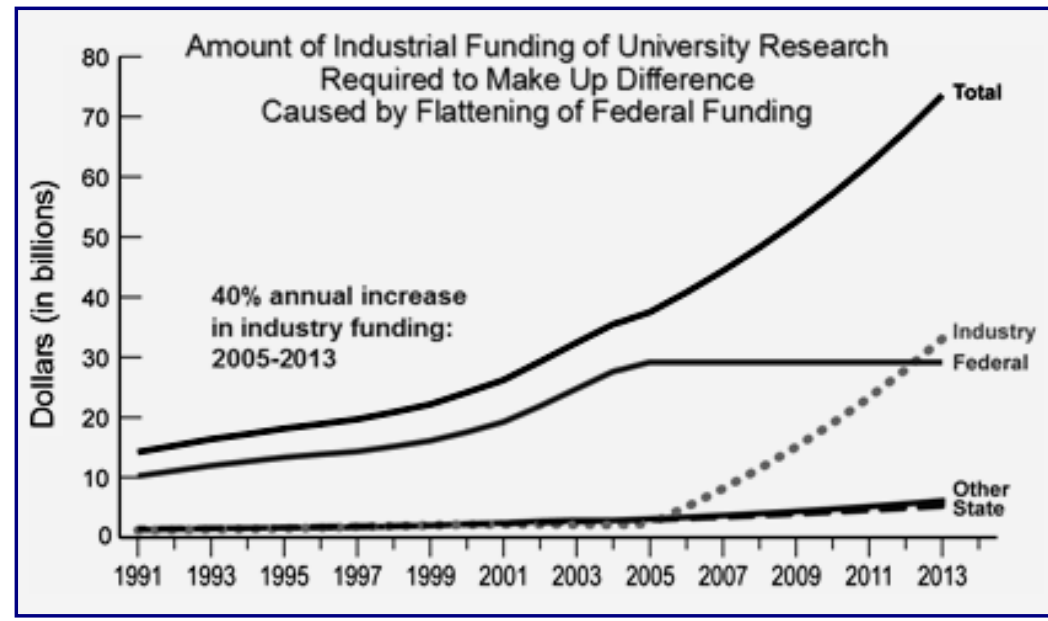

Fiqure 7

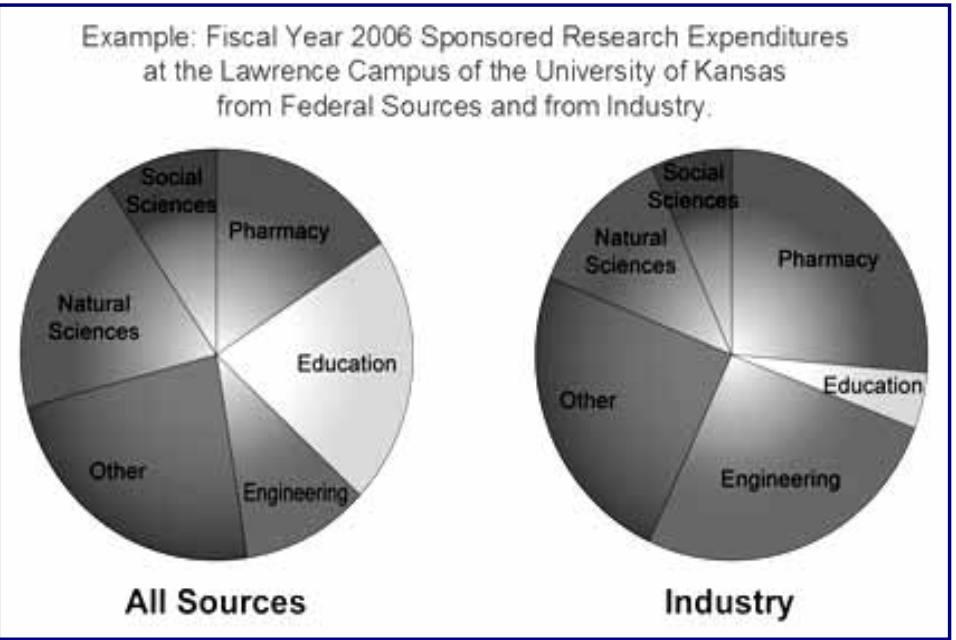

Figure 8

fields of study?

- What happens to the mix of basic versus applied research?

- Does the geographic distribution of research funding change?

The impact on the fields of study should be obvious. Fig. 8 shows the distribution of research funding on the Lawrence campus of the University of Kansas when broken down by federal funding (by far the largest source) and industrial funding. As you might expect, a shift in funding source from federal to industrial results in a shift to engineering and pharmacy, with a corresponding reduction in the social sciences, natural sciences, and education. In short, the fields with more opportunity for applied research benefit.

This raises the second of the unintended consequences relating to basic versus applied research in general. Fig. 9 graphs industrial $R \& D$ spending broken down into basic research, applied research, and development. First, note that the lion's share of industrial R\&D is for "D." Further note that basic research constitutes only a small fraction (about 5\%), and it grew by only $6 \%$ over the period of time shown.

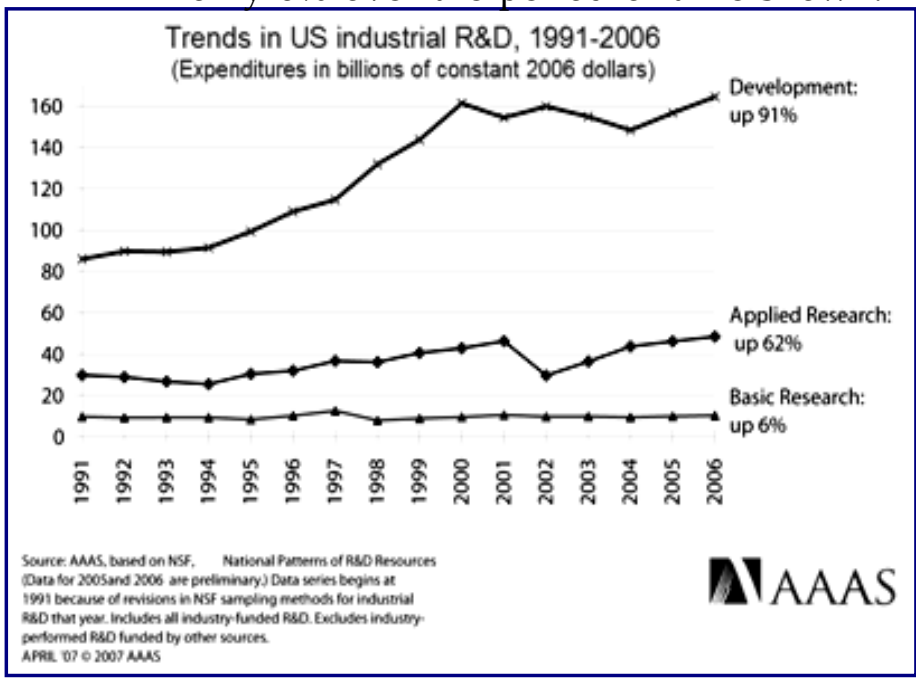

Figure 9 


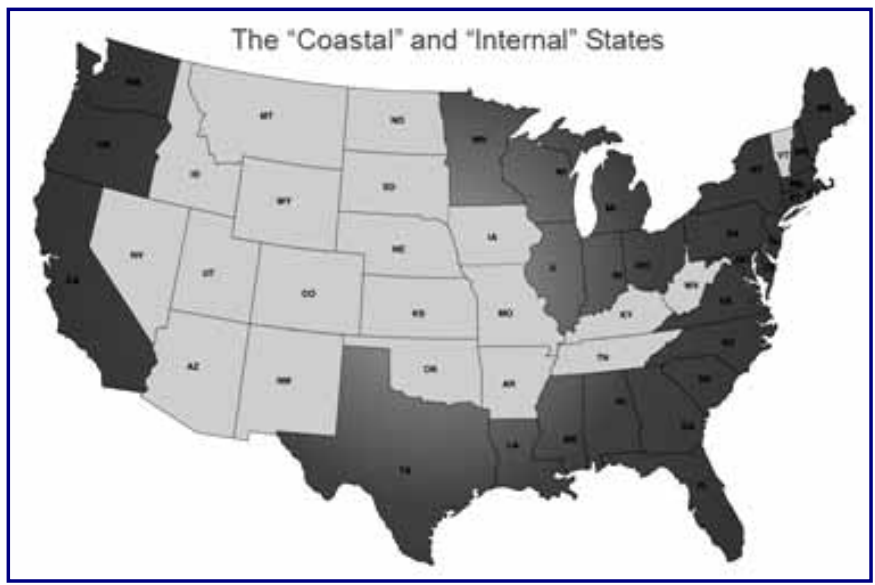

Figure 10

to geography. We in the Midwest are keenly aware that the "coastal states" garner proportionally more research dollars, federal laboratories, prestigious awards, etc. So to address this question with respect to the scenario about industrial funding replacing federal funding of university research, we arbitrarily sorted the states into a "coastal" group and an $75 \%$ of federal funding is for basic "internal" group. This was based simply research. To a first approximation, on whether a state bordered the Atlantic industry funds applied research and or Pacific Oceans or the Great Lakes. Fig. development, while the federal government funds basic research.

In the scenario presented earlier, where industrial funding replaces flattened federal funding of research, if industry continued to spend only $5 \%$ of its budget on basic research there would be a drop of $\$ 19.4$ billion by 2013 in basic research funding to universities.

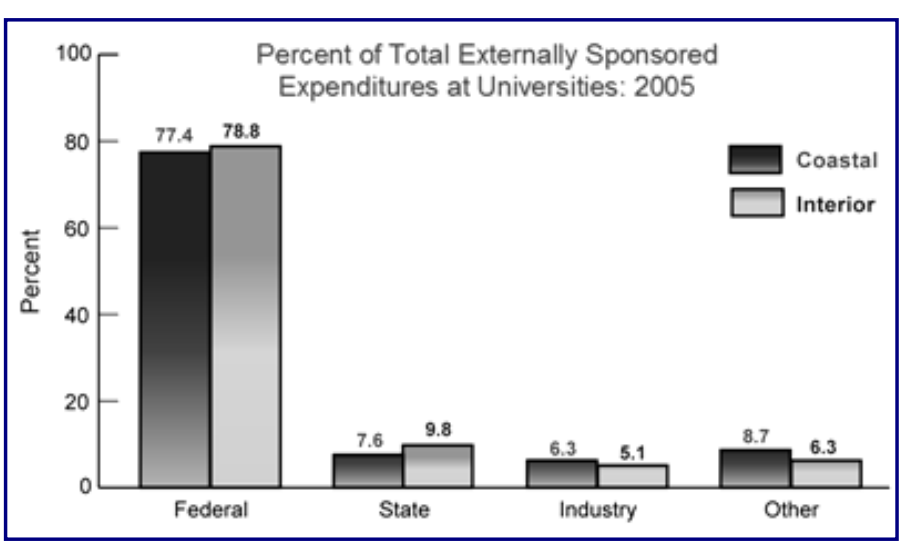

Figure 11 This would have serious consequences for 10 is a map of the states so divided. the future.

The third unintended consequence relates they are coastal in our definition.) $85 \%$ of

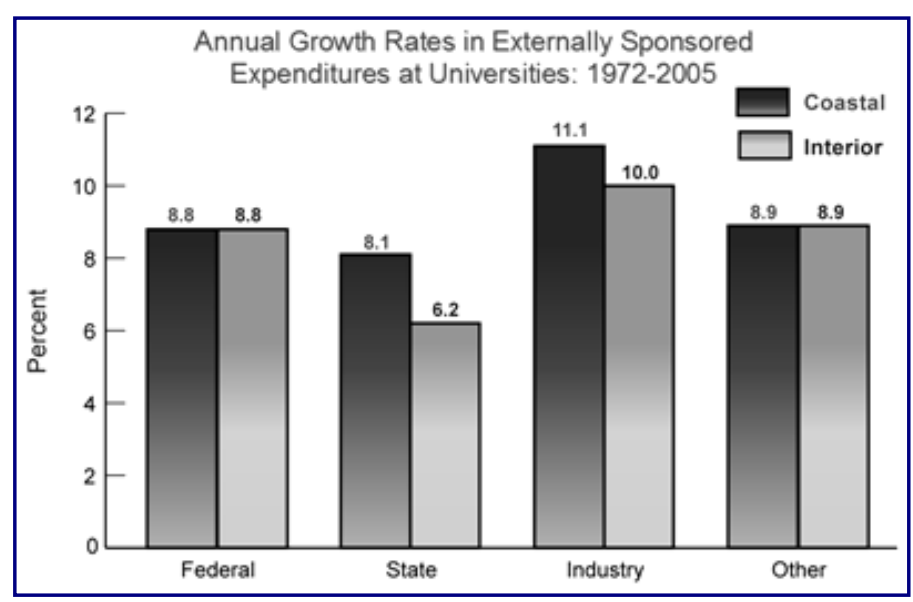

Figure 12 all U.S. research funding is conducted in the coastal states.

Fig. 11 shows the percentage of university research funding by source divided between the coastal states and the interior states. There are some small differences in the distribution of funds based on source between the coastal group and the interior group, but the interior states have a slightly 
larger percentage of their funding coming from federal sources than do the coastal states.

Fig. 12 shows the growth rates broken down the same way. Both state and industrial funding have been growing more rapidly on the coasts than in the interior. So taking the growth rates and the distribution of funding by source, and using the same projection as before with industrial funding replacing flattened federal funding, we find that total $R \& D$ funding in the interior states falls from $15 \%$ of the total today to $13.6 \%$. This is a $10 \%$ reduction and a potential loss of $\$ 1.2$ billion to the interior states. So the problem of unequal distribution of research funding is exacerbated by a shift from federal sources to industrial sources. Universities in the coastal states pick up additional research funding at the expense of the interior states.

\section{Summary}

None of this is intended to say that industrial funding of research is not important. It absolutely is, and we in academia and the country in general need industrial collaborations. But if one asks the question "Can industry make up for a reduction in federal funding of research?" the answer is "Very unlikely." Not only is it very unlikely, there are some negative unintended consequences even if it were to happen.

The question we should be asking is not so much "could it" but "should it?" Basic research is crucial to the future of our society, and universities are where it is happening. To maintain our leadership as a nation, we must fund curiosity-based research that is not driven by agendas or intentional outcomes. This is the source of the great ideas and ultimately the great technological innovations that have given the U.S. the standard of living we all enjoy.

Going back to basics often works. In 1945, Vannevar Bush wrote: “Basic research is essentially non-commercial in nature. It will not receive the attention it requires if left to industry. ...The simplest and most effective way in which the government can strengthen industrial research is to support basic research and to develop scientific talent." ${ }^{4}$ Amen.

\section{Appendix:}

Excerpts of Remarks by Dr. John Marburger, Director, Office of Science and Technology Policy, Executive Office of the President

AAAS Policy Forum, May 2007, Washington D.C.

"I believe we can do all the R\&D we need to do, and very much of what we want to do, but I do not believe we can accomplish this the way we would like to do it, namely by simply appropriating more federal funds."

"I cannot see how such an expansion [NIH budget doubling in 5 years] can be sustained by the same business model that led to its creation. New capacity can only be sustained by new revenue sources."

"The economics of university-based research are beginning to change to a new model with diversified sources of revenue. Federal science policy should encourage this change."

"Not only will it enable an expanded research enterprise, it will also promote development of capacity in areas likely to produce economically relevant outcomes."

"Moreover, economists have documented a positive correlation between industrial research investment and national economic productivity, and to the extent this correlation 
indicates a causal relationship, increased industrial research will be good for the economy."

"The message here is that federal funding for science will not grow fast enough in the foreseeable future to keep up with the geometrically expanding research capacity, and that state and private sector resources should be considered more systematically in formulating federal science policy."

"The level of industrially supported basic and applied research at universities remains low, however, relative to its potential."

\section{References}

1. Wiley, John D., “Why We Won't See Any Public Universities 'Going Private,'" in The

Privatization of Public Universities: Implications for the Research Mission, Merrill Advanced Studies Conference Report No. 110, (M. Rice, Ed.), pp. 1-9, Valley Falls KS, July 1921, 2006.

2. Marburger, John, presentation to the AAAS Policy Forum, Washington DC, May 2007.

3. Crow, Michael, "The Way Forward," presented at the Commission on Technology Transfer (COTT) Summer Meeting, National

Association of State Universities and Land Grant Colleges (NASULGC), Kansas City MO, June 17-20, 2007.

4. Science: The Endless Frontier, Vannevar Bush, 1945. 